\section{Multilocular Giant Radicular Cyst of Maxilla Mimicking Keratocystic Odontogenic Tumor}

\section{Sir,}

Radicular cysts (RCs) are the most common inflammatory odontogenic lesions of the jaws originating from Hertwig's epithelial root sheath (52\% to 68\%). ${ }^{1,2}$ The keratocystic odontogenic tumors (KCOTs) are intraosseous neoplasms of the jaws and arise from dental lamina. ${ }^{3,4}$ RCs and KCOTs are similar in terms of coexistence with tooth, asymptomatic presentation and multilocular and unilocular appearance. However, treatment methods are different. Recurrence rate of KCOT is higher (25\% to $60 \%$ ), so wider excisions may be required. ${ }^{3,5}$

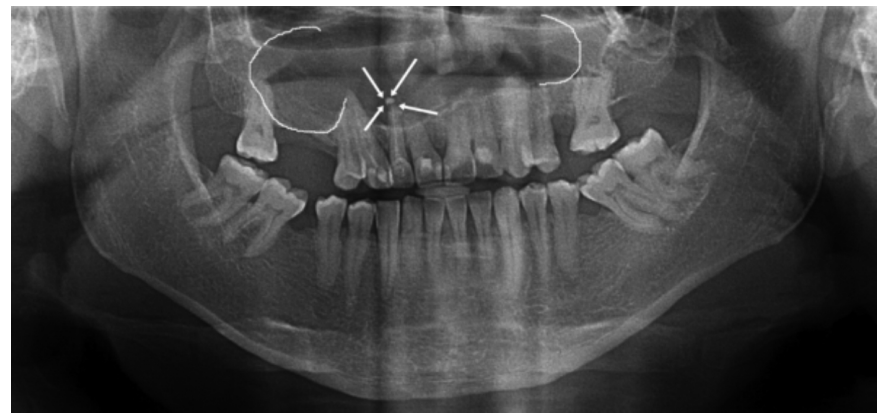

Figure 1: The canal filling exceeds the right lateral dental apex and a multilocular cystisseen.
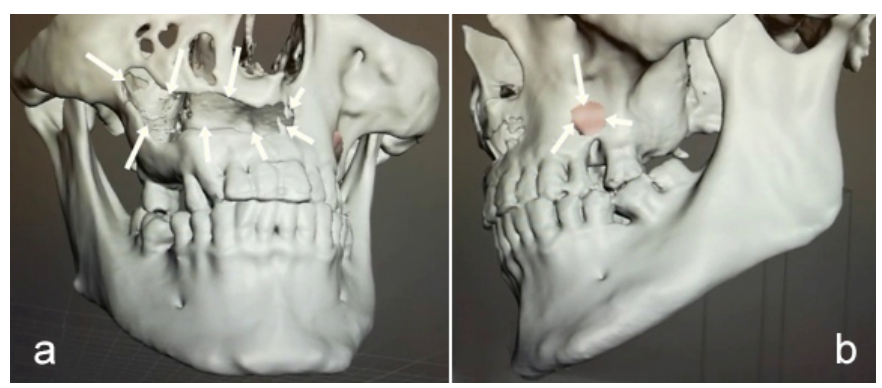

Figure 2: Perforated buccal cortex of maxilla; (a) Right: $38 \times 5 \times 7$ mm; (b) Left: $5 \mathrm{~mm}$.

A 32-year male patient was referred to the Department of Oral and Maxillofacial Surgery, Faculty of Dentistry, Ordu University, Turkey for routine dental examination. The lesion was asymptomatic and detected on routine intraoral radiographs. Panoramic radiography revealed a giant, multilocular radiolucent lesion in the maxilla with smooth surface. It was associated with all the maxillary teeth, and the nose floor was not visible. The canal filling exceeded the right lateral dental apex, and a multilocular cyst was seen (Figure 1). Clinical examination revealed oral mucosa to be normal in colour, and there was no swelling or tenderness at palpation. Oral hygiene was poor with grade 3 stains and calculus. A light-yellow colour liquid was collected by aspiration. The patient was advised for cone beam CT (CBCT).
This revealed an osteolytic lesion with sclerotic margin, measuring about $2.2 \times 3.1 \times 5.1 \mathrm{~cm}$ in dimensions in the maxillary area (Figure 2). Buccal cortical plate was perforated from left first incisor to right second molar; and $5 \mathrm{~mm}$ diameter hole was made in left maxillary area (Figure $2 \mathrm{a}, \mathrm{b}$ ). Thinning of nasal floor, minimal thinning of the buccal cortex, and association with the right maxillary sinus was present (Figure 3).

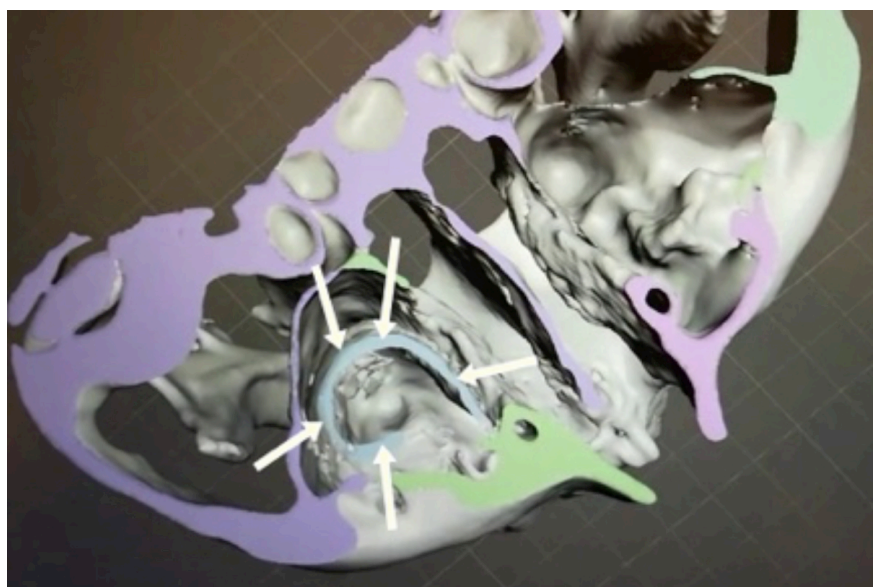

Figure 3: A $2.2 \times 3.1 \times 5.1 \mathrm{~cm}$ radical cyst associated with maxillary sinus (arrows).

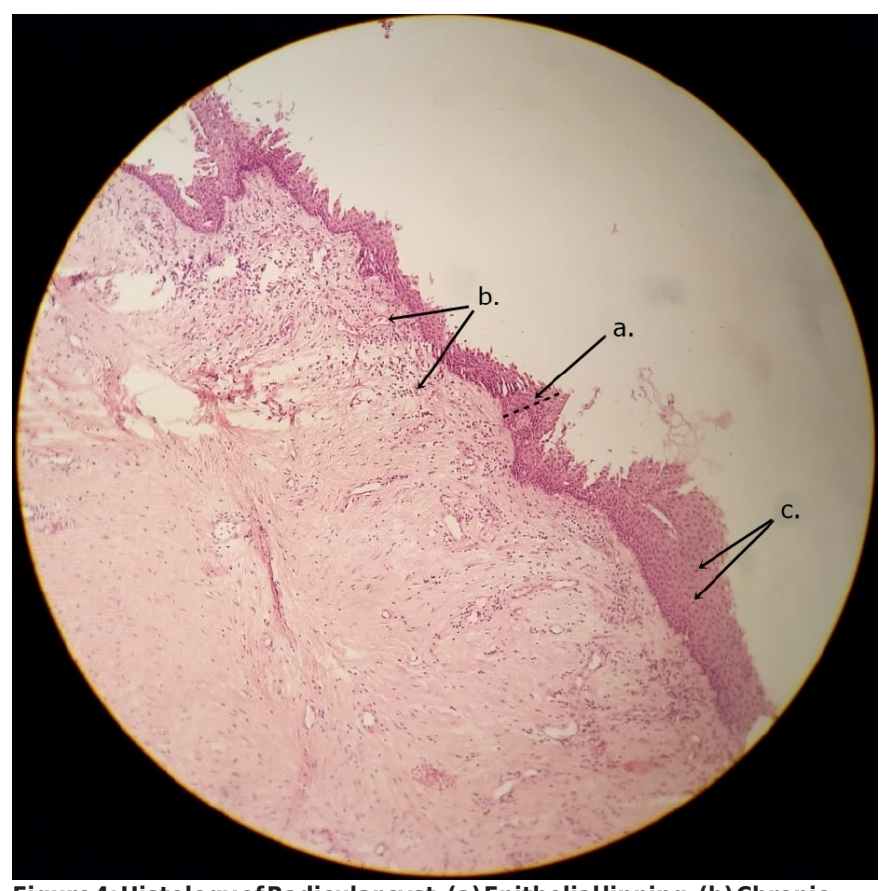

Figure 4: Histology of Radicular cyst. (a) Epithelial linning, (b) Chronic inflammatory cells mm, (c) Acute inflammatory cells.

Electric and thermal pulp vitality testing showed negative responses in right first incisor, so endodontic treatment was performed. After that, the patient was informed of all possible complications that might occur during or after surgery, and signed consent was obtained.

Cyst was enucleated and 1/3 apical resection was applied to maxillary right first incisor under general anesthesia. Then, it was decided to extract it because the tooth was mobile after 
apical resection. Excised tissue was sent for histopathological investigation. The epithelial lining of the cysts (Figure 4a) was partly intact and focally thickened, and was lined by nonkeratinised stratified squamous epithelium, and infiltrated with inflammatory cells (Figure 4 b, c). RC was finally diagnosed on histopathological evaluation.

RCs can be confused with KCOTs and the pathological diagnosis of these cysts is important to avoid unnecessary bone cutting and extraction of teeth.

\section{CONFLICT OF INTEREST:}

No potential conflict of interest was reported by the authors.

\section{AUTHORS' CONTRIBUTION:}

ECS, BC: Designed this study and wrote the manuscript. BC, AY: Treated this case and operated the patient.

\section{REFERENCES}

1. Riachi FTC. Effective management of large radicular cysts using surgical enucleation vs. marsupialisation. IAJD 2010; 1:44-51.

2. Deshmukh J, Shrivastava R, Bharath KP, Mallikarjuna R. Giant radicular cyst of the maxilla. BMJ case reports 2014;

2014 :bcr2014203678. doi: 10.1136/bcr-2014-203678.
3. Pogrel MA. The keratocystic odontogenic tumor. Oral and maxillofacial surgery clinics of North America 2013; 25(1):21-30, v.

4. Chrcanovic BR, Gomez RS. Recurrence probability for keratocystic odontogenic tumors: An analysis of 6,427 cases. Cranio-Maxillo-Fac Surgery 2017; 45(2):244-51. doi: 10.1016/j.jcms.2016.11.010.

5. Bahadure RN, Khubchandani M, Thosar NR, Singh RK. Radicular cyst of primary tooth associated with maxillary sinus. BMJ Case Rep 2013; 2013. doi: 10.1136/bcr-2013009146.

Efe Can Sivrikaya ${ }^{1}$, Burak Cezairli ${ }^{1}$ and Ahmet Yilmaz ${ }^{2}$

${ }^{1}$ Faculty of Dentistry, Karadeniz Technical University, Turkey ${ }^{2}$ Department of Otorhinolaryngology, Medical Park Ordu Hospital, Turkey

Correspondence to: Dr. Efe Can Sivrikaya, Faculty of Dentistry, Karadeniz Technical University, Turkey E-mail: efecans@msn.com

Received: December 02, 2019; Revised: April 10, 2020; Accepted: May 13, 2020

DOI: https://doi.org/10.29271/jcpsp.2020.11.1236 